\title{
ANTI-CRISIS PERSONNEL MANAGEMENT IN THE PROCESS OF ENSURING THE ECONOMIC SECURITY OF THE ENTERPRISE
}

\author{
Stepan MELNYK (1) ${ }^{*}$, Natalia SHUPRUDKO (D) 2 , Iryna KOLOSOVSKA (D) ${ }^{3}$, \\ Ihor BEREST (1) ${ }^{4}$, Mykhaylo PASICHNYK (iD 5 \\ ${ }^{1}$ Faculty number 2, Lviv State University of Internal Affairs, Lviv, Ukraine \\ ${ }^{2}$ Department of Management and Tourism of Chernivtsi Trade and Economic Institute \\ of Kyiv National Trade and Economic University, Chernivtsi, Ukraine \\ ${ }^{3}$ Department of Public Administration, Lviv Regional Institute of Public Administration \\ of the National Academy of Public Administration under the President of Ukraine, Lviv, Ukraine \\ ${ }^{4,5}$ Faculty of Media Communications and Entrepreneurship, Ukrainian Academy of Printing, Lviv, Ukraine
}

Received 29 October 2019; accepted 10 February 2020

\begin{abstract}
Crisis phenomena in many countries of the world do not allow enterprises to develop. Enterprises have to face permanent threats and risks that significantly reduce the current level of their economic security, the problem of creating a protection system, that is, an integrated system of economic security has become a priority. The aim of the article is to determine the impact of the crisis on the management process and the efficiency of personnel use as the basis for the development of anti-crisis solutions, the implementation of which should provide the necessary level of economic security for the enterprise. The results of our study allowed us to identify possible options that ensure the effective implementation of anti-crisis personnel management, focused on restoring the level of economic security necessary for the functioning and development of the enterprise. It was found that in the process of implementing anti-crisis personnel management it has a number of features caused by both the difference in the impact of the crisis, that is, the presence of positive and negative consequences, and a significant list of external and internal factors that must be taken into account when developing each individual anti-crisis solution.
\end{abstract}

Keywords: anti-crisis management, personnel management, economic security, enterprise, security.

JEL Classification: C50, M12, M30, M21.

\section{Introduction}

In the context of the global and national economies crisis, when enterprises have to face permanent threats and risks that significantly reduce their current level of economic security, the problem of creating a protection system, that is, an integrated system of economic security has become a priority. Under such circumstances, almost all enterprises proactively created security systems that allow them to ensure the safety of their activities with varying degrees of effectiveness. The main efforts of enterprises are primarily aimed at ensuring the protection of the territory, production and administrative facilities, means of production, raw materials, finished products and vehicles from unlawful encroachments both by criminal groups and as a result of criminal actions by unscrupulous personnel. On the one hand, the functioning of such a system can reduce the likelihood of some of the possible threats arising, on the other hand, it must be taken into account that in modern conditions the number and list of key risks and threats have changed significantly. The internal state of the environment among the staff reflects the level of efficiency of the entire enterprise. In modern conditions, when the role of an employee in an enterprise is becoming increasingly important, the issue of anti-crisis personnel management is very relevant. Crimes in the economic sphere began to be of an intellectual nature, and their areas of activity were financial activity, enterprise policy and strategy, business management mechanisms, information sphere, law, innovative activity, equipment and technologies, etc. In criminal schemes, corrupt officials and representatives of foreign firms often play a key role, and then the existing security system does not allow reliable protection of enterprises from threats and risks. The aforementioned

*Corresponding author. E-mail: stepanmelnyk@yahoo.com 
actualizes the need to apply anti-crisis management as such, which makes it possible to recognize the moment of the onset and development of the crisis and make adequate decisions in order to restore and maintain the necessary level of economic security of the enterprise. The main purpose of the study is to determine the main management measures that will prevent the formation of a crisis and ensure the economic security of the enterprise. The main tasks of our study are: to identify the main factors that are determining for the implementation of anti-crisis personnel management; to form a mechanism for making an anti-crisis management decision in the process of managing economic security; to form a model of a hierarchy of options to ensure the economic security of the enterprise. For our research, we will apply such methods as: induction, deduction, balance, systematization, synthesis, mathematical analysis, morphological analysis, which will allow us to justify and form possible options that provide effective implementation of anti-crisis personnel management.

\section{Literature review}

Economic security of the enterprise and personnel management are very relevant today among researches of leading scientists. For example, at the present level Avanesova and Chuprin (2017) characterizes the economic security of the enterprise.

Interesting is the study by Kovalenko (2016), which considered the main approaches to the essence of economic security of the enterprise.

In support of the thesis that there are, for example, how many different areas of management research and economic security are available, the study Falovych (2013).

Also, the contributions of Brovkina (2015), Nikitina (2011), Ianioglo and Polajeva (2017), Novikov and Novikova (2014) and Zwolak (2017) in the development of enterprise economic security.

To date, a significant amount of scientific work has been devoted to studies of the problem of improving personnel management at the enterprise. In particular, for example, Akhmetshin et al. (2018) considered the theoretical and methodological aspects of the personnel management process at production enterprises, however, our study justifies this process more mathematically.

Through Browser / Server Design, HR was reviewed by Zhang (2015), who created a framework to help management at all levels standardize the HR process. In turn, our study allows us to determine the best option through the mathematical apparatus to effectively implement this process in the context of ensuring economic security.

An interesting study is Rahim and Herman (2017), who considered the possibility of mobilizing personnel to bring the enterprise out of crisis. Our study in this context is more strategic, since it provides for the prevention of a crisis and the implementation of all possible measures to ensure the safety of the enterprise.

The European approach to the development and management of personnel at the enterprise was considered by
Stoyanova et al. (2019), who identified the key problems that today exist in the process of personnel management.

Khalina et al. (2019) do not currently have legal authority to manage the economy and management. Contribution, our early training for personnel management.

Sylkin et al. (2019) examined the anti-crisis management system in the context of enterprise security. Given their contribution, our study is distinguished by its emphasis and determination of possible options for making an effective anti-crisis management decision.

The process of dismissal of personnel in the context of preventing crisis development and in the context of anticrisis measures was considered by Bychkov (2016). We propose to consider the prevention of such a phenomenon and the search for optimal measures.

Ahammad (2017) considered the specifics of the functioning of the personnel management process itself, against which we propose to consider the process of functioning of the personnel management system through the anti-crisis policy of the enterprise.

The impact of the economic crisis on personnel management was studied by Nurgali (2017) in the context of improving the overall enterprise management system.

It should also be noted that such scientists as Genkin and Nikitin (2013), Sinyavets (2011) and Veshin (2015), who made a significant contribution to the development of the research of personnel management in the enterprise, should be noted.

Given the contribution of other scientists, we propose to consider personnel management for anti-crisis measures. Separately, we strive to achieve optimization in determining the possible options that will ensure the effective implementation of this process and will be focused on restoring the level of economic security necessary for the functioning and development of the enterprise.

\section{Research model}

The practice of functioning business structures convincingly shows that the most important role in a market economy is played by the crisis factor, which is manifested primarily in mass unprofitableness and low rentability of production, price and structural imbalances, insufficient competitiveness, unsatisfactory structure of the balance sheet at the enterprise level, and working capital deficit, imbalances in reproduction processes, insolvency, and the like.

Despite the negative perception of the crisis, not only at the micro level, in the scientific literature there are excellent opinions regarding the essence of this concept in relation to business entities. So, in the scientific literature, one can identify the direction according to which this concept is interpreted as the uncertainty that threatens the existence of the enterprise. Characteristic of this approach is the definition given by Barton (1993), who characterizes the enterprise crisis as "a large-scale, unpredictable event that leads to potentially negative results. This event and its consequences can cause serious damage to the entire 
organization: employees, products, communications, finances and reputation".

The basis of another approach is the results of scientific research, which see exclusively negative trends in the enterprise crisis, which cause a deterioration in the basic parameters of its functioning. For example, Strekalov (1993) define an enterprise crisis as a loss of solvency, competitiveness, deviation of actual results from the planned ones (this applies to production volumes, sales, cash receipts, expenses, profit, profitability).

So, Pauchant and Morin (1996) argue that the function of the crisis is positive, as it allows enterprises to learn, to mobilize efforts to change.

In our opinion, the approaches defined above, due to the multifaceted and ambiguous role of the crisis in the functioning of each individual enterprise, complement each other, qualitatively and comprehensively characterize its essence. At the same time, in accordance with the goal defined above, our task is to examine in more detail the crisis and, accordingly, anti-crisis management, in relation to one of the most important resources of the enterprise personnel.

Before concentrating on this aspect, we propose carefully consider the process of crisis development, that is, determine its key stages. So, a simple (elementary) component of the crisis is a crisis phenomenon - one of the first and most important symptoms of the development of an enterprise crisis. A crisis phenomenon is a transition from stability to deterioration of any of the parameters characterizing the state of the enterprise as a system. In essence, individual crisis phenomena do not cause a constant and deep destabilization of the enterprise, they are a consequence of changes in individual systems and internal and external environments, but, in turn, tend to increase and give rise to other crisis phenomena. If the enterprise does not respond to the occurrence of crisis phenomena (and this happens almost always), then their number is growing, and the processes acquire a negative connotation - a transition to a crisis situation occurs.

A crisis situation is an increase in the number of interconnected crisis phenomena, which leads to a slight deterioration in the performance of the enterprise, but does not cause the destruction of the self-preservation system. Like any other systemic education, the enterprise operates in constant self-regulation. If in the process of activity crises occur, then during a certain time self-regulation succeeds, the recovery processes and the necessary proportions are maintained within certain limits or with a slight deviation. This indicates that the support mechanisms for adaptability, flexibility and stability, which ensure a return of the system to either a previous equilibrium state or a new equilibrium state, remain intact. However, if the number and volume of crisis phenomena are constantly growing, the system of self-regulation is imperfect, then the disorder (deviation from the equilibrium state) increases, contradictions accumulate, the internal mechanism and forces of self-regulation weaken, and the system loses the possibility of an independent return to the state

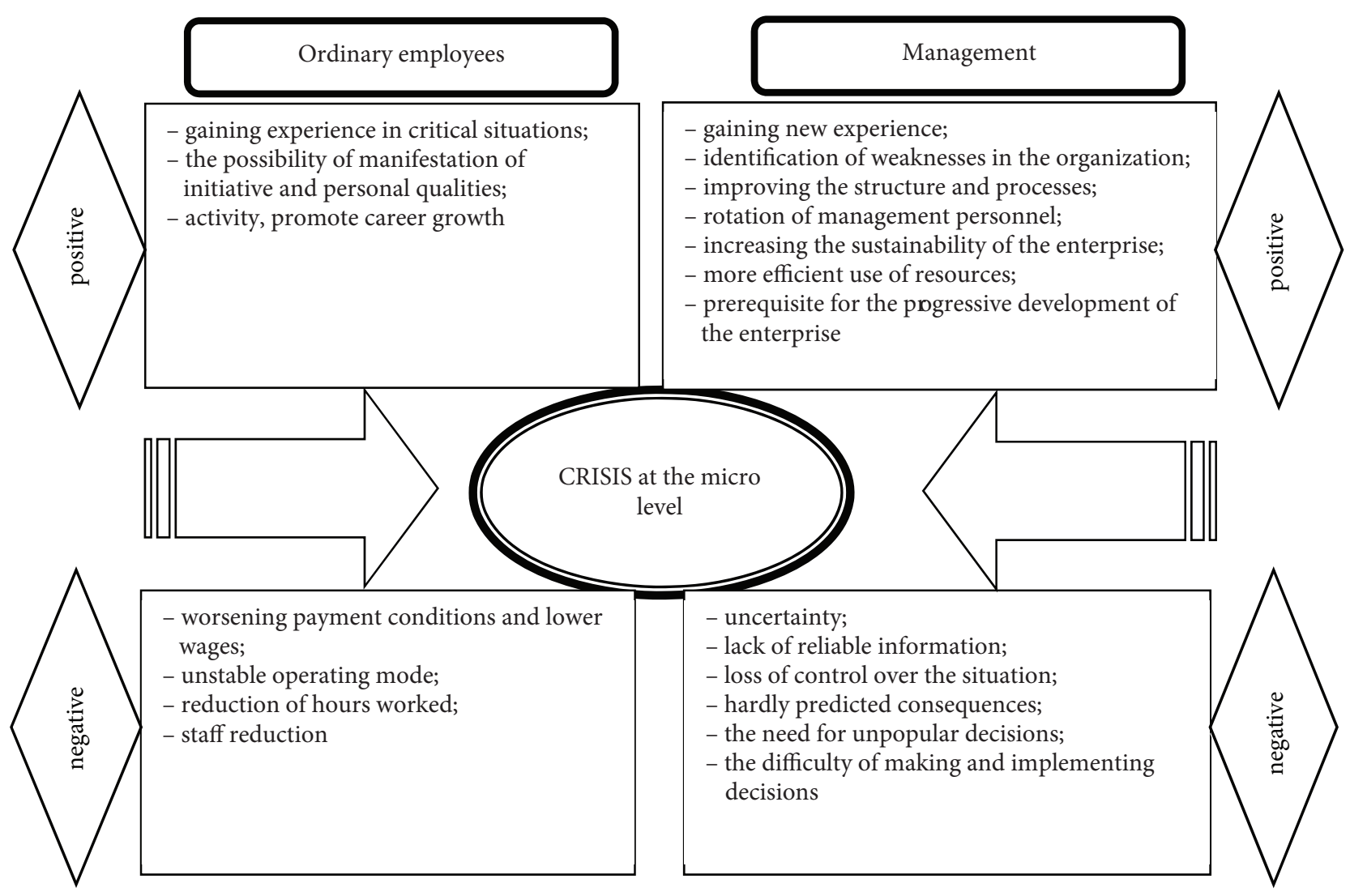

Figure 1. Impact of the crisis on the personnel of the enterprise (source: created by authors) 
of equilibrium. It is at the stage of the destruction of the self-regulatory system that it is advisable to talk about the transition from a crisis development to a crisis situation.

The crisis state is a pile of disagreements between the structure, volumes of activity, enterprise processes and the market situation, which leads to a further increase in the number of crisis phenomena and the deterioration of the financial condition. The crisis state indicates the presence and negative impact of external and internal threats; they were not promptly identified and eliminated by the economic security system of the enterprise.

In our opinion, it is important for the development of appropriate methodological foundations of anti-crisis management to identify the development of the crisis precisely at the stage of the phenomenon and the situation, because this is what makes the reduction of losses from its implementation. Equally important is the fact that the identification and further recognition of the stages of development depends to the greatest extent on the personnel of the enterprise.

It is worth noting that many experts pay special attention in crisis situations to the role of the leader. So, for example, Lagadec (1993) notes that most leaders perceive the crisis in the same way as an emergency, collisions with problems that go beyond the usual framework; the need to act accurately in the absence of guidelines, give meaning to individual and collective actions; crisis is an emergency, accompanied by destabilization.

In our point of view, the crisis should be considered not only in relation to enterprise management, that is, top and middle managers, but, above all, in general with respect to all employees. In addition, we are convinced that in accordance with the existing and described above key approaches to the essence of the enterprise crisis, the impact of the crisis can be either negative or positive, which is reflected in Figure 1. For clarity, the formation of the results of the impact of the crisis on the personnel of the enterprise, it is conditionally divided into two groups: "ordinary employees" and "management".

It should be clarified that the positive effect of the crisis is difficult to display in figures and it is more of a qualitative nature and is reflected in the experience that has been acquired unheard of.

Among the positive consequences of the crisis, the most significant are for both groups - the acquisition of experience and the emergence of prerequisites for development: for employees because of the possibility of identifying and realizing individual qualities that can contribute to their career growth, and for managerial staff - improvement structure and principles of the enterprise. In turn, the negative consequences can be of a different nature: from the destabilization of the situation within a few days to the liquidation of the enterprise, that is, the loss of a job for each employee.

Positive or negative consequences of the crisis require the development and implementation of certain anticrisis solutions, that is, the implementation of anti-crisis management, which is specific and significantly different in the conditions of each individual enterprise.

A theoretical study was carried out that allowed us to identify a number of the most common approaches to the essence of anti-crisis management:

- as a component of general management is aimed at the implementation of sequential measures to diagnose, prevent, and eliminate the consequences of crisis phenomena;

- the management system has a comprehensive, systemic nature and is aimed at early detection of the crisis and the development of countermeasures;

Priority is the adaptation to changes in the external and internal environment.

We agree with the opinion of foreign and domestic scientists, in particular N. Tulenkov (1998), who argues that any management of the organization should be anti-crisis, that is, built on the risk and danger of crisis situations, and then in the process of developing anti-crisis solutions, that is, any decisions in in relation to the personnel of the enterprise, it is necessary to take into account the totality of factors whose source of origin is both external and internal environment.

We have identified the main factors influencing the crisis management of personnel in the enterprise (Figure 2).

Separately, it should be noted the differences in personnel compared with other resources that must be taken into account in the anti-crisis management process:

- employees of the enterprise, as a result of their conscious and unconscious actions, can be a source of crisis;

- a person is endowed with intelligence, and then is capable of self-improvement and development, contributes to the independent solution of some problems;

- the reaction of workers to external influences (management) can be negative, cause resistance and lead to the emergence and deepening of the crisis;

- the subjects of security is the employee of the enterprise, that is, their responsibilities include the development and implementation of anti-crisis management decisions;

- the employees of the enterprise act as security objects, because they are a source of the emergence and spread of the crisis and they also need protection.

Summarizing it can be argued that the basis of anti-crisis personnel management is the process of making managerial decisions, the implementation of which should be aimed at styling the situation, restoring stability and stability of financial and economic activities, that is, ensuring the necessary level of economic security of the enterprise, while taking into account factors influencing on personnel as a subject and security object. The solution to this problem is quite complicated, because it is connected with the need to coordinate the interests of ordinary workers, management, owners, and environmental actors. 


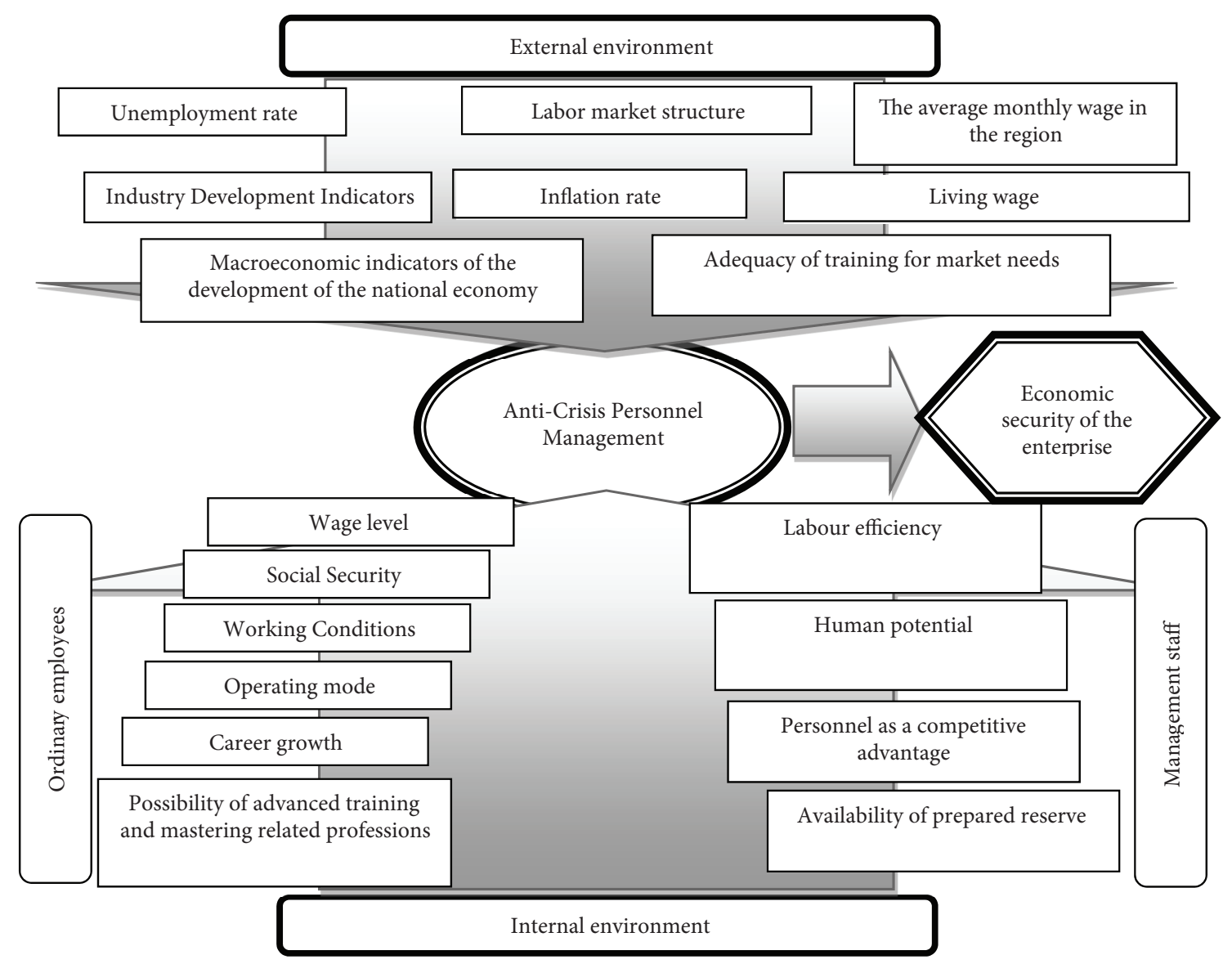

Figure 2. Factors that are decisive for the implementation of anti-crisis personnel management (source: created by authors)

We will subsequently determine the essence of the mechanism of managerial decision-making in the process of managing the economic security of the enterprise, which provides, on the basis of determining the actual level of security in general and in terms of the main functional components, the development of a certain number of alternative options for anti-crisis management decisions in accordance with a certain algorithm (Figure 3).

Decision making in the process of managing economic security is characterized by a number of significant differences:

- based on baseline information on the level of security and possible threats;

- should provide not only the achievement of tasks in a comprehensive system of economic security of the enterprise, but also ensure the development of the enterprise, that is, be consistent with its functioning strategy;

- decisions on a separate functional component cannot reduce the level of security relative to another;

- the costs of implementing a specific decision to ensure the level of security necessary for development should be optimal and meet the effect of their implementation;

- the effect of the implementation of decisions in the process of managing economic security consists in ensuring the established level of security at which the enterprise as a system functions stably and develops in the main areas of activity, the negative impact of the external and internal environment through the identification and neutralization of possible threats is reduced;

- management of economic security is a continuous process that accompanies all life stages of the existence of the enterprise, and then the adoption and implementation of the decision should be accompanied by control, which involves assessing the level of security and threats to determine the results of the implementation of a particular decision and implement its adjustment.

An important place in the personnel management system is postponed by the choice of an effective management decision. The key is to evaluate all possible options and choose the best. A better model for evaluating alternative management decisions in the context of economic security should include:

- formation of a list of alternative options and their mathematical designation;

- interverting between options;

- through the calculation and formation of the reach and dependence matrix, we streamline the priority of using individual options to ensure the economic security of the enterprise; 


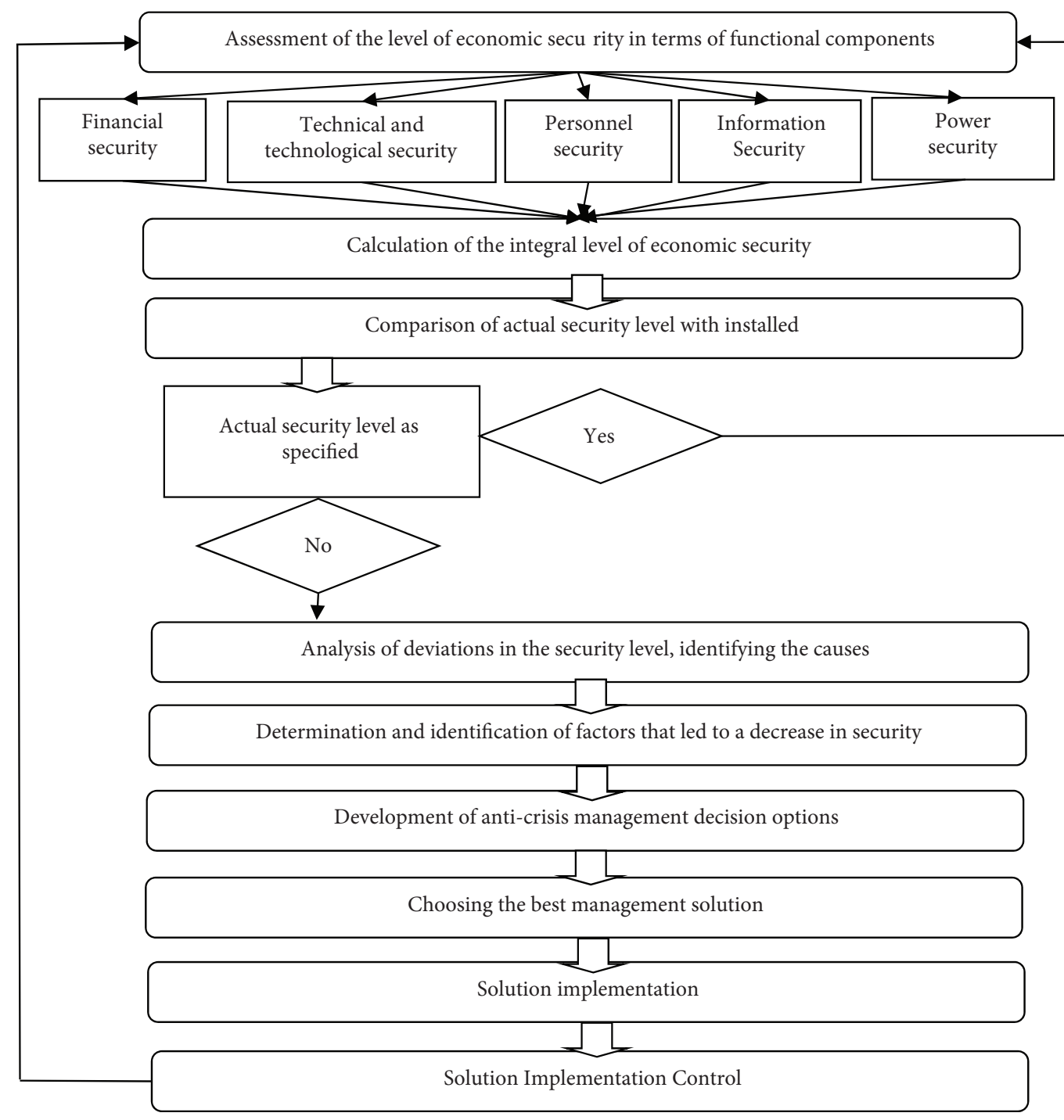

Figure 3. Factors that are decisive for the implementation of anti-crisis personnel management (source: created by authors)

- evaluate and set the weight of each option;

- evaluate the utility of each alternative and choose the best.

\section{Data}

Given the specifics of personnel, in a market economy it becomes a key resource and competitive advantage of this enterprise, and taking into account the totality of certain external and internal factors that must be taken into account when developing each anti-crisis solution, we have identified options for activating anti-crisis personnel management, the application of which will allow timely adoption and implementation of anti-crisis management decisions:

- development of a crisis response program;

- motivation and incentives for staff for activity and initiative in unforeseen situations;

- changes in the organizational structure in order to increase the effectiveness of employee actions;

- staff development.
For clarity, the mathematical designation of each option is supplemented by its mnemonic name (Table 1).

Table 1. The list of alternative options and their mathematical designation (source: developed by author)

\begin{tabular}{|c|l|c|}
\hline $\begin{array}{c}\text { Mathematical } \\
\text { notation }\end{array}$ & \multicolumn{1}{|c|}{ Option Name } & $\begin{array}{c}\text { Mnemonic } \\
\text { name }\end{array}$ \\
\hline$Z_{1}$ & $\begin{array}{l}\text { development of a crisis response } \\
\text { program }\end{array}$ & $\mathrm{BBP}$ \\
\hline$Z_{2}$ & $\begin{array}{l}\text { motivation and incentive of } \\
\text { staff for activity and initiative in } \\
\text { unforeseen situations }\end{array}$ & PPT \\
\hline$Z_{3}$ & $\begin{array}{l}\text { changes in the organizational } \\
\text { structure in order to increase the } \\
\text { effectiveness of employee actions }\end{array}$ & CVT \\
\hline$Z_{4}$ & staff development & PVL \\
\hline
\end{tabular}

The options we have identified for enhancing anti-crisis personnel management, the application of which will allow timely adoption and implementation of anti-crisis 
management decisions, was chosen as a result of a survey of a significant number of experts from top management.

\section{Results and discussions}

The subset of factors $Z_{1}$ (development of a crisis response program) and possible relationships between them are presented in the form of a directed graph (Figure 4).

Based on the graph presented above, we construct a binary dependence matrix $\mathrm{A}$ for the set of vertices $Z_{1}$ as follows (1) (Bartysz, 2009): $a_{i j}=\left\{\begin{array}{l}1, \text { if criterion } i \text { depends on the criterion } j ; \\ 0, \text { if criterion } i \text { doesn't depend on the criterion } j .\end{array}\right.$

For convenience, we place the matrix A with dimensions of $4 \times 4$ elements in the table (Table 2), adding to it an information line and a column with the names of the threats.

Table 2. Binary dependency matrix (source: developed by author)

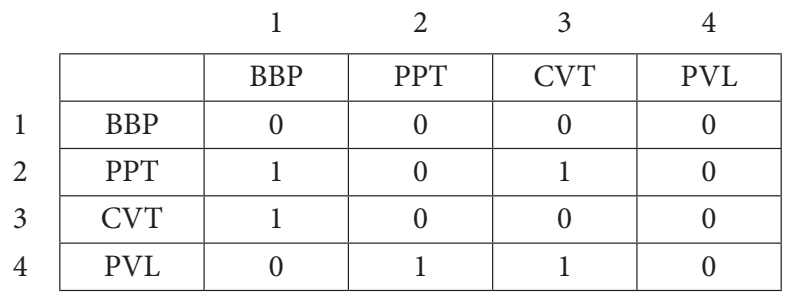

Using the matrix A, we construct the reachability matrix as follows. We form the binary matrix $(I+A)$, where I is the identity matrix. As a result, the reachability matrix must satisfy the condition (2) (Bartysz, 2009):

$$
(I+A)^{k-1} \leq(I+A)^{k}=(I+A)^{k+1} .
$$

In practice, its construction is reduced to filling in a table (Table 3), similar to the one above, the binary elements of which are determined by the following rule (3):

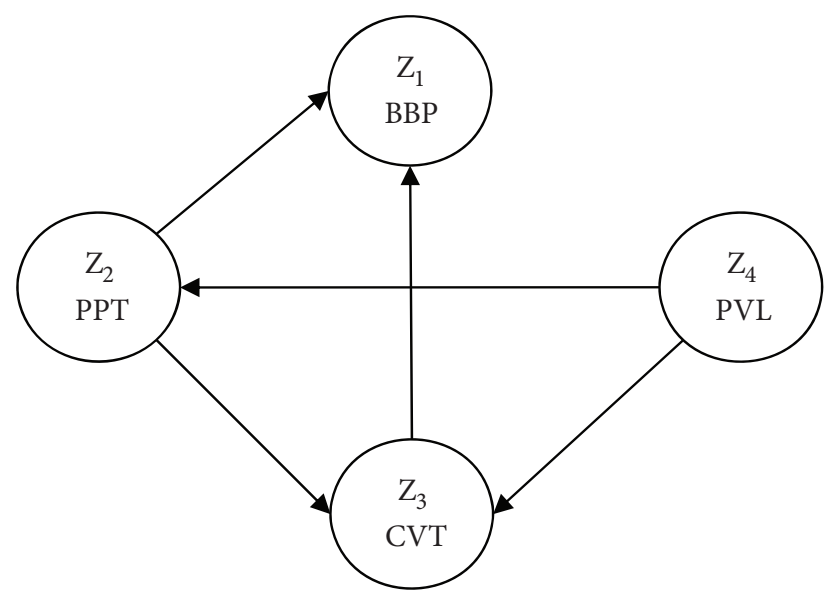

Figure 4. The graph of relationships between options for ensuring the economic security of the enterprise (source: developed by author)

$$
B_{i j}=\left\{\begin{array}{l}
1, \text { if from } i \text { can go in } j ; \\
0, \text { in another way. }
\end{array}\right.
$$

Table 3. The reach matrix (source: developed by author)

\begin{tabular}{l|c|c|c|c|c|}
\multicolumn{1}{c}{} & \multicolumn{1}{c}{1} & \multicolumn{1}{c}{2} & 3 & 4 \\
\cline { 2 - 6 } 1 & & BBP & PPT & CVT & PVL \\
\cline { 2 - 6 } 2 & BBP & 1 & 0 & 0 & 0 \\
\cline { 2 - 6 } 3 & PPT & 1 & 1 & 1 & 0 \\
\cline { 2 - 6 } 3 & CVT & 1 & 0 & 1 & 0 \\
\cline { 2 - 6 } 4 & PVL & 0 & 1 & 1 & 1 \\
\cline { 2 - 6 } & & &
\end{tabular}

The vertex $z_{j}$ is reached with the vertex $z i$ if there is a path in the graph (Figure 4) that leads from the vertex $z \mathrm{i}$ to the vertex $z_{j}$. Such a peak is called reachable. Denote the subset of similar vertices by $S\left(z_{i}\right)$. Similarly, the vertex $z_{i}$ is the predecessor of the vertex $z_{j}$ if it reaches its vertex. Let the set of predecessor vertices form a subset of $P\left(z_{i}\right)$.

Finally, the section of the subsets of reachable and predecessor vertices, that is, a subset (4) (Bartysz, 2009):

$$
R(z)=S\left(z_{i}\right) \cap P\left(z_{i}\right),
$$

the vertices of which are not reached from any of the vertices of the set $Z_{1}$, the remaining ones determine a certain level of the hierarchy of priority actions of threats assigned to these vertices. An additional condition for this is to ensure equality (5) (Bartysz, 2009):

$$
P\left(z_{i}\right)=R\left(z_{i}\right) .
$$

Performing the totality of the above actions gives the first level (the lowest in terms of the importance of influencing the process under study) of the threat hierarchy. To determine it, on the basis of the preliminary matrix, we construct a Table 4 .

Table 4. Calculation table (source: developed by author)

\begin{tabular}{|c|c|c|c|}
\hline$i$ & $S\left(z_{\mathrm{i}}\right)$ & $P\left(z_{\mathrm{i}}\right)$ & $S\left(z_{i}\right) \cap P\left(z_{i}\right)$ \\
\hline 1 & 1 & $1,2,3$ & 1 \\
\hline 2 & $1,2,3$ & 2,4 & 2 \\
\hline 3 & 1,3 & $2,3,4$ & 3 \\
\hline 4 & $2,3,4$ & 4 & 4 \\
\hline
\end{tabular}

The second column of this table is the number of unit elements of the corresponding rows of the access matrix, the third is the number of unit elements of the columns of this matrix. Equality (5) is fulfilled for option 4 (Saati, 1993) - staff development. According to the method of analysis of hierarchies, this option refers to a low level of priority. Further Table 4 we remove rows 4 , and in the $i$-th columns, cross out the number 4 . We get the Table 5 , which is the basis for calculating the second iteration of the number of options that define the next level of the hierarchy. 
Omitting all the intermediate calculations, in accordance with the methodology, the priority was given to the application of individual options for the economic security of enterprises, which allowed us to obtain a hierarchically structured model (Figure 5).

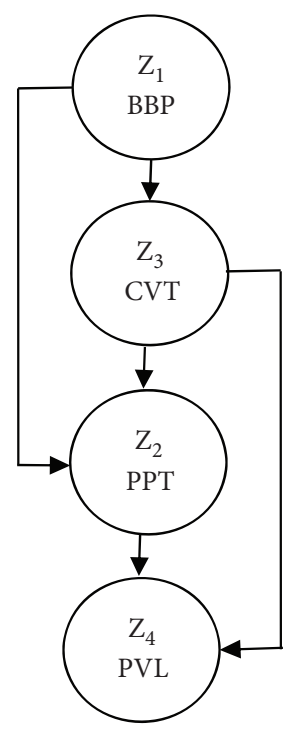

Figure 5. The model of the hierarchy of options for ensuring the economic security of the enterprise

At the next stage of the study, we determine the possibility of ensuring the economic security of enterprises by using the matrix-by-pair comparison method to the advantage of options. For this purpose, we will draw up a table for evaluating alternatives for the options defined above (Table 5).

The components of the normalized main eigenvector of the matrix of pairwise comparisons (Table 5) determine the specified weights of the options:

$$
S_{1}=0.56 ; S_{1}=0.06 ; S_{1}=0.28 ; S_{1}=0.1 \text {. }
$$

Table 5. Estimation of alternatives by Pareto set factors (source: developed by author)

\begin{tabular}{|c|c|c|c|c|}
\hline \multirow{2}{*}{ Options } & \multirow{2}{*}{ Weight } & \multicolumn{3}{|c|}{ Assessing alternatives by factor } \\
\cline { 3 - 5 } & & $\mathrm{A}$ & $\mathrm{B}$ & $\mathrm{C}$ \\
\hline BBP & 0.56 & 33 & 33 & 34 \\
\hline PPT & 0.06 & 20 & 40 & 40 \\
\hline CVT & 0.28 & 40 & 40 & 20 \\
\hline PVL & 0.1 & 30 & 30 & 40 \\
\hline
\end{tabular}

Additional explanation requires the formation of alternative options. Since the weight of the first options is maximum - 0.56, it is logical that in further calculations it will have the greatest impact on the economic security of the enterprise, it has been repeatedly confirmed. Despite this, in our opinion, it is not advisable to limit ourselves to defining this priority option, but in order to ensure the economic security of enterprises, it is necessary to search for other ways. To this end, in alternative options, the proportion of the first option is almost equal, that is, we level its priority effect.

To find the value of the utility functions, we compose matrices of pairwise comparisons for the advantage of options $A, B, C$ relative to the options of the Table 5 . The consistency of the results is feasible according to the priority vectors $\lambda_{\max }$, the $I U$ consistency index and the $W U$ consistency relation. We get the following results (Table $6,7,8,9)$.

Table 6. Calculation table (source: developed by author)

\begin{tabular}{|c|c|c|c|}
\hline BBP & A & B & C \\
\hline A & 1 & 1 & $1 / 2$ \\
\hline B & 1 & 1 & 1 \\
\hline C & 2 & 1 & 1 \\
\hline
\end{tabular}

$\lambda_{\text {max }}=3.05 ; I U=0.03 ; W U=0.05$.

Usefulness of alternatives for BBP option:

$$
u_{31}=0.4 ; u_{32}=0.4 ; u_{33}=0.2 \text {. }
$$

Table 7. Calculation table (source: developed by author)

\begin{tabular}{|c|c|c|c|}
\hline PPT & A & B & C \\
\hline A & 1 & 1 & $1 / 2$ \\
\hline B & 1 & 1 & 1 \\
\hline C & 2 & 1 & 1 \\
\hline
\end{tabular}

$\lambda_{\text {max }}=3 ; I U=0 ; W U=0$.

Usefulness of alternatives for PPT option:

$u_{31}=0.2 ; u_{32}=0.4 ; u_{33}=0.4$.

Table 8 . Calculation table (source: developed by author)

\begin{tabular}{|c|c|c|c|}
\hline CVT & A & B & C \\
\hline A & 1 & 1 & $1 / 2$ \\
\hline B & 1 & 1 & 1 \\
\hline C & 2 & 1 & 1 \\
\hline
\end{tabular}

$\lambda_{\text {max }}=3 ; I U=0 ; W U=0$.

Usefulness of alternatives for CVT option:

$u_{31}=0.4 ; u_{32}=0.4 ; u_{33}=0.2$.

Table 9. Calculation table (source: developed by author)

\begin{tabular}{|c|c|c|c|}
\hline PVL & A & B & C \\
\hline A & 1 & 1 & $1 / 2$ \\
\hline B & 1 & 1 & 1 \\
\hline C & 2 & 1 & 1 \\
\hline
\end{tabular}

$\lambda_{\text {max }}=3 ; I U=0 ; W U=0$.

Usefulness of alternatives for PVL option:

$u_{31}=0.25 ; u_{32}=0.25 ; u_{33}=0.5$. 
The calculations were performed correctly, since the value of the priority vector $\lambda_{\max }, I U$ consistency index, and $W U$ consistency ratio for each of the matrices are within normal limits. According to the method (Bartysz, 2009) of multicriteria evaluation of alternatives, we have: $u_{i j}$ - the utility of the $j$-th alternative $(1,2,3)$ according to the $i$-th option $(1,2, \ldots 4) ; U_{j}$ - multivariate assessment of the utility of the $j$-th alternative (Bartysz, 2009):

$$
U_{j}=\sum_{i=1}^{4} s_{i} u_{i j}, j=1,2,3,
$$

where $u_{i j}$ is the utility of the $j$-th alternative according to the $i$-th option.

In accordance with this, we have the following options for calculating the values of the utility function of alternatives:

$$
\begin{aligned}
& U_{1}=s_{1} \cdot u_{11}+s_{2} \cdot u_{21}+s_{3} \cdot u_{31}+s_{4} \cdot u_{41} \\
& U_{2}=s_{1} \cdot u_{12}+s_{2} \cdot u_{22}+s_{3} \cdot u_{23}+s_{4} \cdot u_{42} \\
& U_{3}=s_{1} \cdot u_{13}+s_{2} \cdot u_{23}+s_{3} \cdot u_{33}+s_{4} \cdot u_{43} .
\end{aligned}
$$

Substituting the values obtained above into the expressions, we obtain:

$U_{1}=0.56 \times 0.26+0.06 \times 0.2+0.28 \times 0.4+0.1 \times 0.25=0.295 ;$

$U_{2}=0.56 \times 0.33+0.06 \times 0.4+0.28 \times 0.4+0.1 \times 0.25=0.346$;

$U_{3}=0.56 \times 0.41+0.06 \times 0.4+0.28 \times 0.4+0.1 \times 0.5=0.360$.

According to the method used, to ensure the economic security of the enterprise, it is advisable to use an alternative $U_{3}$ for which the value of the utility function is maximum. In this case, as follows from previous studies and Table 1, to ensure the economic security of the enterprise, in addition to developing a program of action in crisis situations, the priority is the development of personnel.

\section{Conclusions}

Ensuring the sustainable development of the enterprise in a market environment is rapidly and multidirectional changing, it is impossible without security. The price of this issue is especially important, because it is today that there is an increase in the level of dynamism and uncertainty of the external environment, which significantly affect all areas of activity, as well as the process of monitoring internal changes is becoming more complicated, and the inability to provide the necessary level of efficiency of economic activity is being complicated.

According to the results of a theoretical study, it was found that in the process of implementing anti-crisis personnel management it has a number of features caused by both the difference in the impact of the crisis, that is, the presence of positive and negative consequences, and a significant list of external and internal factors that must be taken into account when developing each individual anti-crisis solutions.

It is proved that ensuring the economic security of enterprises requires the implementation of crisis management, in particular due to personnel. The personnel of the enterprise, being the most valuable resource and characterized by a number of distinctive characteristics, simultaneously performs the functions of an object and a security subject. The basis of anti-crisis personnel management is the process of making managerial decisions. Possible options are identified that ensure the effective implementation of anti-crisis personnel management, focused on restoring the level of economic security necessary for the functioning and development of the enterprise.

An important result of the obtained factors is the determination that, in the presence of several variants of anti-crisis management decisions, it is possible to make the necessary calculations, evaluate each of them and choose the best one.

The data we have obtained show that with a sufficient number of alternatives, the manager at the enterprise, can model which of them should be applied.

The main result of our research is to identify possible options that ensure the effective implementation of crisis management personnel, focused on restoring the necessary for the functioning and development of the level of economic security of the enterprise. Also, we are offered how to choose the best ones.

The study is not without limitations. At this point in time, the results of the study were applied in practice only in small enterprises. In the future, it is necessary to conduct a more detailed analysis of the specifics of the anticrisis personnel management system at large enterprises.

\section{Author contributions}

The authors contributed equally.

\section{Disclosure statement}

The authors do not have any conflict of interest.

\section{References}

Ahammad, T. (2017). Personnel management to human resource management: How HRM Functions. Journal of Modern Accounting and Auditing, 13(9), 412-420 https://doi.org/10.17265/1548-6583/2017.09.004

Akhmetshin, E., Brager, D., Pokramovich, O., Andreyko, M., \& Alenikova, M. (2018). Modern theoretical and methodological approaches to personnel management in manufacturing enterprises. Revista: Espacios. Management, 39(31), 11-15.

Avanesova, N., \& Chuprin, Y. (2017). Enterprise economic security: essential characteristics of the concept. Innovative Technologies and Scientific Solutions for Industries, (1), 98-102. https://doi.org/10.30837/2522-9818.2017.1.098

Barton, L. (1993). Crisis in organizations: Managing and communicating in the Heat of Chaos (pp. 2-12). Cincinnati, Ohio, Soth-Western.

Bartysz, M. (2009). Research of operations. Part 3: Decision Making and Game Theory: A Handbook (278 p.). Lviv: VU LNU them. I. Franko.

Brovkina, Yu. O. (2015). Approaches to the study of the enterprise economic security concept. Economy: Realities of time, 1(17), 122-128. 
Bychkov, V. (2016). Human resources: textbook. Moscow: Norma: SIC INFRA-M.

Falovych, A. (2013). Modern trends in defining the essence of enterprise economic security. Socio-economic Problems and The State, 1(8), 271-278.

Genkin, B., \& Nikitin, I. (2013). Human resource management: Textbook. Norma: SIC INFRA-M.

Ianioglo, A., \& Polajeva, T. (2017). The essence and phases of the comprehensive system of ensuring the economic security of enterprise. International Journal of Learning and Change, 9(1), 59-74. https://doi.org/10.1504/IJLC.2017.10005203

Kovalenko, O. V. (2016). Approaches to the definition of enterprise economic security. Economic Journal of Zaporizhzhia State Engineering Academy, 1, 65-72.

Khalina, O., Bazyliuk, V., Chornenka, O., Krasilych, I., \& Korzh, M. (2019). Formation of organizational support for the management of the economic security of engineering enterprises: methodical and practical aspects. Business: Theory and Practice, 20, 317-328. https://doi.org/10.3846/btp.2019.30

Lagadec, P. (1993). Un nouveau champ de responsabilite pour les dirigeants. The Virtual Corporation. Rev francaise de gestion. Paris, 108, 110. New York.

Nikitina, A. V. (2011). Development of theoretical foundations of enterprise economic security. Ukrainian Scientific Production Journal "Sustainable Economic Development", 3, 82-85.

Novikov, A., \& Novikova, M. (2014). Modeling of financial and eco-nomic security of transport enterprises based on factor analysis. Nauka ta Progress Transport, 6(54). https://doi.org/10.15802/stp2014/32769

Nurgali, A. (2017). The impact of economic crisis on personnel management. European Science, 4(26), 54-57.

Pauchant, T., \& Morin, E. (1996). La gestion systemique des crises et la prevention de la contr-production. Rev francaise de gestion, 108, 80-99. Paris.
Rahim, M., \& Herman, A. (2017). Features of personnnel management of a crisis enterprise. Education and science in the 21 century. Articles of the International Scientific and Practical Conference, 151-154.

Saati, T. (1993). Decision making (Hierarchy Analysis Method): Per. from English. Moscow: Radio and communications publishing, 278.

Sinyavets, T. (2011). Theoretical aspects of optimization of personnel management system. Bulletin of Omsk University, 24(2), 78-84. Series: The Economy. Omsk State University.

Stoyanova, T., Koev, S., Stoyanov, Ph., Zhyvko, Z., \& Laptiev, V. (2019). Strategic management of the personnel development. Academy of Strategic Management Journal, 18(3).

Strekalov, O. (1993). Crises in the organization and project management: Textbook (160 p.). Kazan: KSTU.

Sylkin, O., Kryshtanovych, M., Zachepa, A., Bilous, S., \& Krasko, A. (2019). Modeling the process of applying anti-crisis management in the system of ensuring financial security of the enterprise. Business: Theory and Practice, 20, 446-455. https://doi.org/10.3846/btp.2019.41

Tulenkov, N. (1998). Crisis management. Personnel, 6, 19-25.

Veshin, V. (2015). Human resource management. Theory and practice: the textbook for high schools. Moscow: Prospect.

Zwolak, J. (2017). The financial security of small- and medium-sized enterprises in Poland. Ekonomski Pregled, 68(4), 399-412.

Zhang, X. (2015). The enterprise personnel management system based on B/S Design. 10th International Conference on Broadband and Wireless Computing, Communication and Applications (BWCCA). https://doi.org/10.1109/BWCCA.2015.43 